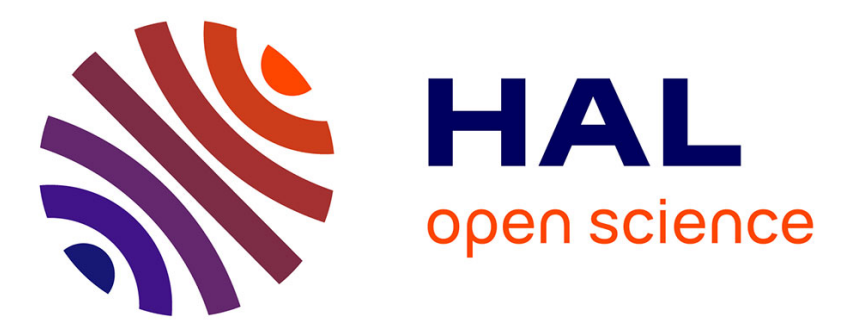

\title{
In situ quantification of diverse titanium dioxide nanoparticles unveils selective endoplasmic reticulum stress-dependent toxicity
}

Marina Simon, Gladys Saez, Giovanna Muggiolu, Magali Lavenas, Quentin Le Trequesser, Claire Michelet, Guillaume Devès, Philippe Barberet, Eric Chevet, Denis Dupuy, et al.

\section{To cite this version:}

Marina Simon, Gladys Saez, Giovanna Muggiolu, Magali Lavenas, Quentin Le Trequesser, et al.. In situ quantification of diverse titanium dioxide nanoparticles unveils selective endoplasmic reticulum stress-dependent toxicity. Nanotoxicology, 2017, 11 (1), pp.134-145. 10.1080/17435390.2017.1278803 . hal-01447226

HAL Id: hal-01447226

https://hal-univ-rennes1.archives-ouvertes.fr/hal-01447226

Submitted on 1 Jun 2017

HAL is a multi-disciplinary open access archive for the deposit and dissemination of scientific research documents, whether they are published or not. The documents may come from teaching and research institutions in France or abroad, or from public or private research centers.
L'archive ouverte pluridisciplinaire HAL, est destinée au dépôt et à la diffusion de documents scientifiques de niveau recherche, publiés ou non, émanant des établissements d'enseignement et de recherche français ou étrangers, des laboratoires publics ou privés. 


\section{In Situ Quantification of Diverse Titanium Dioxide Nanoparticles Unveils Selective Endoplasmic Reticulum Stress-Dependent Toxicity.}

Marina Simon ${ }^{1,2} \ddagger$, Gladys Saez ${ }^{1,2} \ddagger$, Giovanna Muggiolu ${ }^{1,2}$, Magali Lavenas $^{3,4}$, Quentin Le Trequesser ${ }^{1,2,3,4}$, Claire Michelet ${ }^{1,2}$, Guillaume Devès $^{1,2}$, Philippe Barberet ${ }^{1,2}$, Eric Chevet $^{5,6}$, Denis Dupuy ${ }^{7,8}$, Marie-Hélène Delville $^{3,4^{*}}$ and Hervé Seznec ${ }^{1,2 *}$

${ }^{1}$ Université de Bordeaux, Centre d'Etudes Nucléaires Bordeaux Gradignan (CENBG), Chemin du solarium, 33175 Gradignan, France. ${ }^{2}$ CNRS, UMR5797, Centre d'Etudes Nucléaires Bordeaux Gradignan (CENBG), Chemin du solarium, 33175 Gradignan, France. ${ }^{3}$ CNRS, UPR9048, Institut de Chimie de la Matière Condensée de Bordeaux (ICMCB), 87 avenue du Dr. A. Schweitzer, Pessac, F-33608, France. ${ }^{4}$ Université de Bordeaux, Institut de Chimie de la Matière Condensée de Bordeaux (ICMCB), 87 avenue du Dr. A. Schweitzer, Pessac, F-33608, France. ${ }^{5}$ INSERM, ERL440, “Oncogenesis Stress Signaling”, Université Rennes 1, 35000 Rennes, France. ${ }^{6}$ Centre de Lutte Contre le Cancer Eugène Marquis, Avenue de la Bataille Flandres Dunkerque, 35000 Rennes. ${ }^{7}$ INSERM, U869, IECB, Laboratoire ARNA, F-33600, Bordeaux, France. ${ }^{8}$ Université de Bordeaux, U869, IECB, Laboratoire ARNA, F-33600, Bordeaux, France.

Corresponding authors E-mails:

herve.seznec@cenbg.in2p3.fr, marie-helene.delville@icmcb.cnrs.fr 


\title{
In Situ Quantification of Diverse Titanium Dioxide Nanoparticles Unveils Selective Endoplasmic Reticulum Stress-Dependent Toxicity.
}

\begin{abstract}
Although titanium dioxide nanoparticles $\left(\mathrm{TiO}_{2} \mathrm{NPs}\right)$ have been extensively studied, their possible impact on health due to their specific properties supported by their size and geometry, remains to be fully characterized to support risk assessment. To further document NPs biological effects, we investigated the impact of $\mathrm{TiO}_{2} \mathrm{NPs}$ morphology on biological outcomes. To this end, $\mathrm{TiO}_{2} \mathrm{NPs}$ were synthesized as nanoneedles (NNs), titanate scrolled nanosheets (TNs), gelsol-based isotropic nanoparticle (INPs) and tested for perturbation of cellular homeostasis (cellular ion content, cell proliferation, stress pathways) in three cell types and compared to the P25. We showed that $\mathrm{TiO}_{2}$ NPs were internalized at various degrees and their toxicity depended on both titanium content and NPs shape, which impacted on intracellular calcium homeostasis thereby leading to endoplasmic reticulum stress. Finally, we showed that a minimal intracellular content of $\mathrm{TiO}_{2}$ NPs was mandatory to induce toxicity enlightening once more the crucial notion of internalized dose threshold beside the well-recognized dose of exposure.
\end{abstract}

Keywords: Titanium dioxide nanoparticles, morphology dependant toxicology, ER stress, calcium homeostasis, in situ quantification 


\section{Introduction}

The high photocatalytic and super-hydrophilic properties of titanium dioxide nanoparticles $\left(\mathrm{TiO}_{2}\right.$ NPs) have made them popular for a wide variety of applications. Pigment grade titanium dioxide is widely used as a pigment due to its whiteness and high refractive index. It can be found in paints, plastics, paper, inks, food, medicines (pills), and toothpaste. A very common application of $\mathrm{TiO}_{2} \mathrm{NPs}$ is as an additive in sunscreen cosmetics as a UV-attenuating filter agent. $\mathrm{TiO}_{2} \mathrm{NPs}$ have been engineered in terms of shapes and sizes for applications including their use as a functional component in self-cleaning cements, glass and paints; water purification systems, anti-fogging coatings for glass (Chen and Mao 2007, Kaegi et al. 2008, Lee et al. 2010, Sadrieh et al. 2010). Tailoring sphere-shaped to fiber-shaped NPs such as nanowires, nanobelts and nanotubes is very attractive for their properties in photocatalysis, charge transfer and sensing due to their unique structures. $\mathrm{TiO}_{2} \mathrm{NPs}$ are produced in "pseudo-spherical" shape (such as the AEROXIDE P25) and also exist in low-dimensional $\mathrm{TiO}_{2}$ nanomaterials such as one-dimensional nanotubes, nanorods, nanoneedles, nanobelts, and nanowires (Xia et al. 2003, Devan et al. 2012) or two-dimensional nanoplates (Zhuang et al. 2015) and titanate scrolled nanosheets (Liang et al. 2012) with different properties. For example, titanate scrolled nanosheets (TNs) have been recently developed for their exceptional electronic, optical and photocatalytic performance (Schwartzenberg and Gray 2012, Yu et al. 2012). In recent years, many studies have also focused on the biomedical applications of $\mathrm{TiO}_{2} \mathrm{NPs}$ in areas such as cancer therapy, drug delivery systems, cell imaging, genetic engineering, and biosensors (Yin et al. 2013).

Parallel to these promising new applications in industry and in nanomedicine, $\mathrm{TiO}_{2}$ NPs may generate environmental and health risks due to their specific properties 
supported by their size and geometry; this is actually source of great concerns. For many years, $\mathrm{TiO}_{2}$ has been considered as biologically inert, suggesting that environmental or occupational exposure was relatively harmless and effectively cleared out of the body. However, their toxic potential remains largely unclear (Kahru and Dubourguier 2010, Jovanovic 2015, Yu, Sun, et al. 2015). Since NPs are used in therapy, it is a real challenge to detect, track and quantify them in living and biological samples and to correlate this with toxicity effects.

Many studies have reported that $\mathrm{TiO}_{2}$ NPs elicit a toxic response in different biological systems including animals, mammalian cells, model organisms, and bacteria (Rahman et al. 2002, Lewinski et al. 2008, Hamilton et al. 2009, Cai et al. 2011, Wang et al. 2013, Setyawati, Tay, and Leong 2015). Nevertheless, only a few ones have focused on the relationship between NPs morphology and toxicity (Zoroddu et al. 2014). It has been shown that longer $\mathrm{TiO}_{2}$ nanobelts induced higher toxicity to both alveolar macrophages and mice than their shorter, spherical counterparts (Hamilton et al. 2009). Numerous in vitro studies have reported $\mathrm{TiO}_{2} \mathrm{NPs}$ toxicity in various cell types with different observations (Federici et al. 2007, Lai et al. 2008, Li et al. 2008, Zoroddu et al. 2014). As many NPs, $\mathrm{TiO}_{2}$ NPs have been shown to localize within the cells (Osano et al. 2003, Geiser et al. 2005, Simon et al. 2011). It has been reported that a P25 suspension induces an inflammation response in rat lungs. Fibrosis, pulmonary as well as DNA damages have been described (Oberdorster et al. 1994, Donaldson et al. 2001, Sayes et al. 2006, Warheit et al. 2007, Sager et al. 2008, Sun et al. 2012, Zoroddu et al. 2014). $\mathrm{TiO}_{2}$ NPs are also able to generate free radicals and reactive oxygen species (ROS), and raise DNA adduct formation in human lung fibroblasts (Long et al. 2006, Xia et al. 2006, Bhattacharya et al. 2009, Toyooka et al. 2012). In addition, in A549 cells, $\mathrm{TiO}_{2}$ NPs induced mitochondrial injury in a dose-dependent way owing to 
reactive oxygen species generation (Tang et al. 2013). Photogenotoxic potential and genotoxicity have also been reported in different cell systems (Wang et al. 2007, Vevers and Jha 2008, Oesch and Landsiedel 2012). Tong et al. reported the effect of material morphology on the phototoxicity of $\mathrm{TiO}_{2}$ NPs to bacteria Escherichia coli and Aeromonas hydrophila (Tong et al. 2013).

Recent studies report the endoplasmic reticulum stress (ER stress) as a common response in NPs related toxicity with studies on $\mathrm{TiO}_{2}$ NPs (Zhang et al. 2012, Chen et al. 2014, Yu, Chang, et al. 2015). The endoplasmic reticulum (ER) is an important organelle, which plays a role in folding and assembling of cellular proteins, in synthesis of lipids and sterols, and in regulating the balance of the intracellular calcium homeostasis, processes which are all dependent on the ER internal homeostasis. The ER stress also known as unfolded protein response (UPR) refers to an important cellular self-protection mechanism, which can be activated to counteract the cell situation of stress (overloading proteins or direct ER damage). Previous works evidenced an alteration of calcium homeostasis in different cell types after exposure to $\mathrm{TiO}_{2} \mathrm{NPs}_{\mathrm{s}}$ (Koeneman et al. 2010, Simon et al. 2011). To date, only few studies have investigated the relationship between NPs morphology and their toxicity; they however failed in providing any obvious links. Quantifying NPs in biological systems is challenging but essential to elucidate their interactions with the living organisms and the resulting toxicity. Finally, whereas there are evidences of $\mathrm{TiO}_{2}$ NPs toxicity, the involved mechanisms are not yet fully elucidated.

As a consequence, the goal of this paper is to investigate and rationalize the cellular homeostasis responses and ER stress induced by different types of $\mathrm{TiO}_{2} \mathrm{NPs}$ (in terms of shape and size) in different in vitro primary and immortalized human cell populations (endothelial cells, epidermal keratinocytes and immortalized cancerous cells). A careful 
attention was paid to the quantification of the NPs internalization in order to establish a correlation with the subsequent intracellular ion homeostasis, the ER stress response as well as the cell fate (differentiation, proliferation, death).

\section{Methods}

\section{$\mathrm{TiO}_{2} \mathrm{NPs}$ synthesis and characterization}

P25 nanoparticles (P25, AEROXIDE) were kindly provided by Degussa/Evonik and used both for biological tests and as precursor for all the synthesis performed in this study. Titanate scrolled nanosheets (TNs) were produced via hydrothermal process described by Kasuga et al (Kasuga 2006). Briefly, $2 \mathrm{~g}$ of P25 were introduced in a 50 $\mathrm{mL}$ Teflon lined autoclave with $28 \mathrm{~mL}$ of $10 \mathrm{M}$ sodium hydroxide solution, sealed and heated at $130{ }^{\circ} \mathrm{C}$ for $20 \mathrm{~h}$. The white precipitate was washed with nitric acid $(0.1 \mathrm{M})$ and water for neutralization and identified as titanate scrolled nanosheets (TNs). Nanoneedles (NNs) were obtained after a second hydrothermal process applied on the TNs. An aqueous dispersion of $660 \mathrm{mg}$ of TNs was stabilized at $\mathrm{pH} \mathrm{9,} \mathrm{adjusted} \mathrm{at} 30$ $\mathrm{mL}$, and sealed in the Teflon lined autoclave for a hydrothermal treatment at $140{ }^{\circ} \mathrm{C}$ for $72 \mathrm{~h}$ (Nian and Teng 2006). The resulting white powder was then neutralized with water and identified as nanoobjects called Nanoneedles (NNs) all along the paper. Isotropic NPs (INPs) were finally synthesized using gel-sol method.(Sugimoto et al. 2003) Titanium isopropoxide $(0.005 \mathrm{~mol})$ was mixed with triethanolamine $(0.01 \mathrm{~mol})$ and water reaching a final volume of $20 \mathrm{~mL}$. The solution was then sealed in Teflon lined autoclave for a hydrothermal treatment at $140^{\circ} \mathrm{C}$ for $72 \mathrm{~h}$. The obtained white powder was finally washed with deionized water. All the synthesized NPs were kept in aqueous solution avoiding aggregation issues. Mass concentrations were measured by drying a 
known volume of solution and weighting the extracted powder. Suspensions with concentration of $1 \mathrm{mg} \cdot \mathrm{mL}^{-1}$ were finally produced, sonicated and kept in the dark.

The physicochemical properties of $\mathrm{TiO}_{2}$ NPs samples were characterized by standard techniques. Specifically, the primary size and morphological features of $\mathrm{TiO}_{2} \mathrm{NPs}$ were observed using Transmission Electron Microscopy (TEM) using the Hitachi H7650 $(120 \mathrm{kV})$. Powder X-ray diffraction was used to determine the phase composition and crystallite size of each $\mathrm{TiO}_{2}$ NPs and was performed with Philips PW1820 diffractometer. A Zeta potential analyzer (ZetaCompact $\left.{ }^{\circledR}, \mathrm{CAD}\right)$ was used to measure the zeta potential and electrophoretic mobility of each $\mathrm{TiO}_{2} \mathrm{NPs}$ in the different exposure media. The Hydrodynamic diameters were measured using a Dynamic Light Scattering (Vasco, Cordouan technology).

\section{Cell culture and $\mathrm{TiO}_{2} \mathrm{NPs}^{\text {exposure }}$}

Human Epidermal Keratinocytes (HEKn) or Human Umbilical Vein Endothelial Cells (HUVEC), derived from normal human tissues, were obtained from Invitrogen (ThermoFischer Scientific). They were respectively grown in EpiLife ${ }^{\circledR}$ (ThermoFischer Scientific, MEPICFPRF500) or M200PRF® (ThermoFischer Scientific, M200PRF500) complemented with LSGSTM with $100 \mathrm{mg} \cdot \mathrm{mL}^{-1}$ penicillin/streptomycin. EpiLife ${ }^{\circledR}$ medium is a medium prepared without calcium chloride for long-term and serum-free culture of human epidermal keratinocytes supplemented with Human Keratinocyte Growth Supplement (HKGS, S-001-5). M200-PRF® is a sterile liquid medium for the culture of large vessel endothelial cells supplemented with Low Serum Growth Supplement (LSGS, S-003-10). Detailed formulation of these media can be found on the manufactures' web site. HeLa cells (ATCC® CCL-2 ${ }^{\mathrm{TM}}$ ) were obtained from LGCstandards (Molsheim, France) and were grown in DMEM completed $2 \mathrm{mM}$ L-glutamine 
and $100 \mathrm{mg} \cdot \mathrm{mL}^{-1}$ penicillin/streptomycin (ThermoFischer Scientific). HUVEC, HEKn and HeLa cells were grown in defined medium at $37{ }^{\circ} \mathrm{C}$ in a $5 \%(\mathrm{v} / \mathrm{v}) \mathrm{CO}_{2}$ humidified atmosphere and passages are realized at $80 \%$ confluency. The suspensions of $\mathrm{TiO}_{2} \mathrm{NPs}$ were prepared in ultrapure water at a concentration of $1 \mathrm{mg} \cdot \mathrm{mL}^{-1} \cdot \mathrm{TiO}_{2} \mathrm{NPs}$ were dispersed by intense sonication pulses of 1 min at RT $(750 \mathrm{~W}, 20 \mathrm{kHz}$, with $30 \%$ amplitude) using a Vibra-Cell ${ }^{\mathrm{TM}}$ and a dedicated $3 \mathrm{MM}$ conical microprobe (ThermoFischer Scientific). Suspensions were hereby known as "stock suspensions". Stock suspensions were diluted at the appropriate concentration in defined culture medium in order to obtain exposure suspension ranging from 0 to $20 \mu \mathrm{g} . \mathrm{cm}^{-2}$ (final concentration).

\section{Cell preparation for high-resolution ion beam micro-analysis (IBA)}

Cell cultures (HUVEC, HEKn and HeLa) were cultured directly onto ion beam microprobe sample holders as adapted from previous studies (Le Trequesser et al. 2014). Briefly, cells were directly grown at high confluence on $2 \mu \mathrm{m}$-thick polycarbonate foil for 24 hours in appropriate culture medium, and then exposed to $\mathrm{TiO}_{2}$ NPs for 16 to $24 \mathrm{~h}$. Control cells were prepared similarly with no addition of $\mathrm{TiO}_{2}$ NPs. Cells were rinsed once in culture medium, and very briefly rinsed twice in ultrapure water to remove excess of extracellular salts from culture medium. Finally, cells were plunge-freezed at $-150{ }^{\circ} \mathrm{C}$ into liquid nitrogen chilled 2-methylbutane (ReagentPlus, $\geq 99 \%$, Sigma-Aldrich) and freeze-dried using a freeze-dryer (Christ alpha, ThermoFischer Scientific) in two phases: A phase of primary desiccation of 12 to 24 hours $\left(\mathrm{T}^{\circ} \mathrm{C}=-99^{\circ} \mathrm{C}, \mathrm{P}=0.001 \mathrm{mbar}\right)$ followed by a phase of secondary desiccation of 24 hours $\left(\mathrm{T}^{\circ} \mathrm{C}=+40^{\circ} \mathrm{C}, \mathrm{P}=0.001\right.$ mbar $)$. With no contamination and no ionic diffusion, freeze-drying was found to be the most adapted process. 


\section{Ion beam micro-analysis (IBA)}

Single cell quantitative analysis of the chemical element (quantitative analysis and element distribution) were carried out with a high-resolution microprobe beam line (AIFIRA, CENBG) using complementary ion beam analytical techniques ( $\mu$-STIM $\mu$ PIXE). Protocols are described in previous works (Devès et al. 2004, Simon et al. 2011, Le Trequesser et al. 2014).

\section{Cell proliferation}

Cell populations were seeded in six-well plates at a density of 10,000 cells/well for HeLa or 20,000 cells/well for HEKn and HUVEC, respectively. For each condition, the following procedure was used: 8 different wells were prepared (one for each day, numbered 1 to 8 ), filled with the cells and let alone for 24 hours. One well for each counting day was seeded for each condition. After this delay of $24 \mathrm{~h}$ of culture, each cells well was exposed to $2 \mathrm{ml}$ of fresh medium supplemented with the exposure suspensions containing P25, Titanate scrolled nanosheets (TNs), nanoneedles (NNs) or Isotropic NPs (INPs) at a final concentration of $2 \mu \mathrm{g} . \mathrm{cm}^{-2}$. Well 1 was examined after 1 day, well 2 after 2 days and so on, so that the cell culture was not contaminated by any component used to proceed to the counting. Cells were then harvested using $400 \mu \mathrm{L}$ of trypsin-EDTA $0.25 \%(\mathrm{v} / \mathrm{v})$ (Invitrogen). After $5 \mathrm{~min}$ of centrifugation at $1200 \mathrm{rpm}$, the cell pellet was resuspended in an appropriate volume of fresh culture medium. The same volume of Trypan blue was added and $10 \mu \mathrm{L}$ of the cell suspension is counted using a cell counter (TC20, BioRad). The operation was proceeded on the 8 wells, one 
per day. $1 \mathrm{ml}$ of fresh culture medium was added every 2 days in each well. The experiment was performed in duplicate.

For HEKn, the same procedure was used, but cells are counted every two days, because of the slow proliferation rate of keratinocytes.

\section{Quantitative Real-Time PCR}

Total RNA was extracted from cells at different times (from 1 to 24 hours) after NPs exposure using the RNeasy mini kit (Qiagen) according to the manufacturer's instructions. Complementary DNA synthesis from 300-500 ng of total RNA was performed using random hexamer primers and QuantiTect Reverse Transcription kit (Qiagen). Quantitative real-time PCR were realized on a LightCycler ${ }^{\circledR} 96$ (Roche Diagnostics) using the Fast start essential Green master (Roche Diagnostics), according to the manufacturer's instructions. Reaction volumes of $20 \mu \mathrm{L}$ are subjected to the following cycles: a pre-incubation phase $\left(95^{\circ} \mathrm{C}, 10 \mathrm{~min}\right)$, followed by 45 cycles of a 3 step amplification phase $\left(95^{\circ} \mathrm{C}, 10 \mathrm{sec}, 60^{\circ} \mathrm{C}, 10 \mathrm{sec}\right.$ and $\left.72{ }^{\circ} \mathrm{C}-10 \mathrm{sec}\right)$ and finally, a melting phase $\left(95^{\circ} \mathrm{C}, 10 \mathrm{sec}, 65^{\circ} \mathrm{C}, 60 \mathrm{sec}\right.$ and $\left.97^{\circ} \mathrm{C}, 1 \mathrm{sec}\right)$. Results were normalized with the $h G A P D H$ and h18S genes and analyzed using software LightCycler ${ }^{\circledR} 96 \mathrm{SW}$ 1.1 (Roche Diagnostics). The primers sequences used in these experiments are described in Table S3 (supplementary data).

\section{In situ Mitochondrial staining with TMRM (TetraMethylRhodamine)}

TMRM diluted in DMSO was added to the cell culture medium at a final concentration of $500 \mathrm{nM}$. Cells were incubated in presence of $\mathrm{TiO}_{2} \mathrm{NPs}$ for from 1 to 20 hours and 
then with TMRM for $30 \mathrm{~min}$ at $37{ }^{\circ} \mathrm{C}$ in the cell incubator. Cell culture medium was changed and rinsed before observation using live fluorescence microscopy.

\section{In cellulo ER stress detection - CHOP immunodetection}

Cell populations are seeded on glass slides and grown for 24 hours. Then, cells are exposed to $\mathrm{TiO}_{2}$ NPs for 16 or 24 hours. Tunicamycin treatment $(20 \mathrm{~h}$ incubation, 5 $\mu \mathrm{g} \cdot \mathrm{mL}^{-1}$, Calbiochem) is used as positive control for ER stress induction. Tunicamycin, an inhibitor of protein glycosylation, is used as model drug for disrupting the ER homeostasis-induced Unfolded Protein Response (UPR). After exposure, cells were fixed with $2 \%(\mathrm{w} / \mathrm{v})$ paraformaldehyde (Sigma) in phosphate-buffered saline (PBS) medium ( $\mathrm{pH} 7.4$, without $\mathrm{Ca}^{2+}$ and $\mathrm{Mg}^{2+}$, Invitrogen) for $15 \mathrm{~min}$ at room temperature (RT), under agitation. Then, cell permeabilization and saturation were performed using a solution containing $0.2 \%(\mathrm{v} / \mathrm{v})$ Triton X-100 (Sigma), 10\% FCS (Dutscher) in PBS for 30 min., at room temperature. Cells were incubated overnight at $4{ }^{\circ} \mathrm{C}$ with antihuman CHOP mouse monoclonal antibody (L63F7, Cell Signaling) and 2 hours at RT with goat anti-mouse IgG conjugated to AlexaFluor ${ }^{488}$ antibody (Molecular Probes, Invitrogen) at 1/3200 and 1/2000 dilutions, respectively. Cells were then rinsed 3 times with PBS and nuclei stained with $10 \mu \mathrm{M}$ Hoechst ${ }^{33342}$ in PBS. Slides were mounted using Prolong Gold Antifade Reagent (Invitrogen) and visualized on Zeiss AxioObserver Z1 (Carl Zeiss MicroImaging, GmbH).

\section{Cell preparation for transmission electron microscopy (TEM)}

Cells grown on 8-well Labtek II (Nunc) were exposed during $24 \mathrm{~h}$ to $2 \mu \mathrm{g} . \mathrm{cm}^{-2}$ of the different $\mathrm{TiO}_{2}$ NPs. Protocols are described in previous works (Simon et al. 2011). 


\section{Statistical analysis}

Each experiment was repeated at least 3 times, independently. Data from all experiments were analyzed using the "R" software. Comparison between element concentrations in exposed cells were made using non parametric Kruskal-Wallis test in order to test null hypothesis, followed when necessary by a post-hoc Nemenyi test to identify groups presenting differences in their concentration. Relation between calcium, iron and titanium concentrations were tested using a linear model by both ordinary least square regression method (OLS-LM) and an alternative robust fitting of linear model less sensitive to points with a high leverage. Significance was set at $\mathrm{p}<0.05\left(^{*}\right)$.

\section{Results}

\section{Synthesis and physicochemical properties of the different $\mathrm{TiO}_{2} \mathrm{NPs}$}

In the current study, we synthesized $\mathrm{TiO}_{2}$ nanoneedles (NNs) (Nian and Teng 2006), titanate scrolled nanosheets (TNs) (Kasuga 2006) from AEROXIDE P25 (P25, classical spherical shape with heterogeneous crystallinity) as well as isotropic NPs (INPs, pure anatase) from titanium alkoxides (Sugimoto et al. 2003). These $\mathrm{TiO}_{2} \mathrm{NPs}$, along with the AEROXIDE P25, allowed us to examine the effects of material morphologies as well as crystallinity on $\mathrm{TiO}_{2}$ nanotoxicity. Their characteristics are summarized and shown in Figure 1 with representative transmission electron microscopy (TEM) images.

All along the synthesis procedure, the $\mathrm{TiO}_{2}$ NPs were kept in solution to avoid aggregation due to drying. Nevertheless, and despite their negative surface at 
physiological $\mathrm{pH}(\mathrm{pH} 7.4)$, these NPs exhibited a tendency to agglomerate in water and in the different biological media used as illustrated by the hydrodynamic diameter variations (Figure S1). The latter also showed that P25 and TNs were subjected to swift re-agglomeration after sonication as opposed to the much more stable colloidal NNs. The use of different and specific culture media such as EpiLife ${ }^{\circledR}$, M200-PRF ${ }^{\circledR}$ or DMEM strongly modified the behavior and agglomeration state of the NPs. Indeed, TNs and P25 flocculated in such media most likely due to their content in amino acids, vitamins, and inorganic salts (Figure S1).

These observations strongly indicate that the behavior of $\mathrm{TiO}_{2} \mathrm{NPs}$ in biological media can be drastically modified and should be considered an important factor that could influence the results of the toxicity evaluation.

\section{Multi-parametric influences of $\mathrm{TiO}_{2} \mathrm{NPs}$ on cell proliferation}

To evaluate the toxic effects of the different $\mathrm{TiO}_{2} \mathrm{NPs}$, we studied the cell proliferation of the three different cells lines upon exposure to NPs. All TiO 2 NPs (P25, INPs, NNs, TNs) were toxic pointing HUVEC cells and toxicity was both morphology- (Figure 2a) and dose-dependent (Figure S2). The impact of $\mathrm{TiO}_{2} \mathrm{NPs}$ morphology on toxicity was obvious at a concentration of $2 \mu \mathrm{g} . \mathrm{cm}^{-2}$ and after 8 days of exposure. Indeed, P25, INPs and TNs dramatically affected proliferation, whereas NNs were harmless under these conditions. To determine the impact of the exposure dose for each type of $\mathrm{TiO}_{2} \mathrm{NPs}$ a dose response from $0.5 \mu \mathrm{g} . \mathrm{cm}^{-2}$ to $20 \mu \mathrm{g} . \mathrm{cm}^{-2}$ was performed. Toxic effects of INPs and TNs were observed at doses as low as $0.5 \mu \mathrm{g} . \mathrm{cm}^{-2}$ (Figure S2). An exposure dose higher than $20 \mu \mathrm{g} . \mathrm{cm}^{-2}$ was necessary to observe a decrease of the cell proliferation to less than $50 \%$ for NNs, by contrast with the other $\mathrm{TiO}_{2}$ NPs (Figure S2). 
The same sets of $\mathrm{TiO}_{2}$ NPs were also incubated with HEKn (Figure 2b), the resulting proliferation assays indicated that P25, NNs, and INPs exhibited a moderate dosedependent toxicity even after several days. The most striking impact was observed for the elongated TNs, which dramatically and significantly decreased the HEKn viability to about $20 \%$ of that of the control $\left(2 \mu \mathrm{g} \cdot \mathrm{cm}^{-2}\right.$ and 8 days exposure, Figure $\left.2 \mathbf{b}\right)$. Moreover, HeLa cells proliferation was only impaired at the highest doses $\left(>20 \mu \mathrm{g} . \mathrm{cm}^{-}\right.$ ${ }^{2}$ for INPs and $>4 \mu \mathrm{g} . \mathrm{cm}^{-2}$ for TNs) while no significant difference could be seen with P25 or NNs (Figure S2). Thus, according to these observations, $\mathrm{TiO}_{2}$ NPs impact on cell viability/proliferation not only depends on the dose and on the morphology of NPs but also on the cell types.

\section{$\mathrm{TiO}_{2} \mathrm{NPs}$ toxicity is related to the titanium intracellular content}

To define the relationship between toxicity, titanium intracellular concentration and NPs type, we quantified the concentrations of titanium and the overall intracellular ion content (such as phosphorus, potassium, calcium, ...) in single cell using $\mu$-PIXE (Le Trequesser et al. 2014). $\mu$-PIXE was performed on the three different cell types exposed to $\mathrm{TiO}_{2} \mathrm{NPs}$ at $2 \mu \mathrm{g} \cdot \mathrm{cm}^{-2}$ for 20 hours. This analysis revealed a marked heterogeneity of the intracellular titanium content per cell in a given population, and also depending on the nature of $\mathrm{TiO}_{2} \mathrm{NPs}$ and the cell type. (Figure 3). Indeed, titanium intracellular content in HEKn was in average lower than in HUVEC cells. As for example with P25, the intracellular titanium content is 10 times lower in HEKn $\left(0.14+/-0.1 \mu \mathrm{g} . \mathrm{cm}^{-2}\right)$ than in HUVEC (1.36 +/- $\left.0.1 \mu \mathrm{g} . \mathrm{cm}^{-2}\right)$ (Table S1 and S2). Interestingly, a strong correlation was observed between the toxicity level (Figure 2) and the titanium content (Figure 3). NNs, which show no sign of in vitro toxicity towards HUVEC also exhibit a 
significantly low intracellular titanium amount as exemplified by the single cell quantitative analysis (Figure 3c). In the case of HEKn, when the cells were exposed to P25, INPs and NNs they presented the same toxicity reply despite different intracellular titanium contents (Figure 3c) suggesting that a minimal intracellular titanium content in a minimal number of cells per population is necessary but not sufficient to induce in vitro toxicity, which is also strongly dependent on the intrinsic morphology of the NPs.

Finally, the chemical distribution maps of titanium (Ti) at the single cell level (phosphorus distribution was used to delineate the cellular area) in HUVEC (Figure 3a) and HEKn cells (Figure $\mathbf{3 b}$ ) showed high heterogeneity of the titanium content within cell population as well as between the two cell types. NPs toxicity was noticeable when a minimal number of cells containing a minimal amount of titanium per cell is reached (in HUVEC, $>5 \mu \mathrm{g} \cdot \mathrm{cm}^{-2}, \mathrm{P}>0.005$ ).

Thus, $\mathrm{TiO}_{2}$ NPs toxicity with regards to a given cell is a function of the intracellular titanium content most likely conditioned by the ability of the cells to internalize NPs and NPs behavior in biological medium. To confirm this observation, we exposed HEKn to $10 \mu \mathrm{g} \cdot \mathrm{cm}^{-2}$ of $\mathrm{TiO}_{2}$ NPs for 20 hours (Figure 3). The resulting quantitative analysis revealed that the intracellular titanium content was effectively increased but in a limited way suggesting that the in vitro toxicity was much more related to the intracellular content of $\mathrm{TiO}_{2}$ NPs than to the initial exposure dose.

\section{$\mathrm{TiO}_{2} \mathrm{NPs}$ internalization modifies the intracellular ionic homeostasis}

P25 internalization in human primary keratinocytes was previously described to induce an elevated and related accumulation of intracellular calcium (Simon et al. 2011). For HUVEC cells, a clear correlation between toxicity, intracellular titanium and intracellular calcium contents was established (Figure 4) for a NPs dose of exposure of 
$2 \mu \mathrm{g} . \mathrm{cm}^{-2}$ for $16-20$ hours. The results observed for NNs (low titanium and calcium contents) are coherent with the absence of toxicity detected for these $\mathrm{TiO}_{2}$ NPs (Figure 2a and Table S1).

In the case of HEKn, a correlation between the increase of the intracellular calcium content and the internalized titanium content was established when the threshold of 0.01 $\mu \mathrm{g} . \mathrm{cm}^{-2}$ in intracellular titanium content was reached and this for all the types of $\mathrm{TiO}_{2}$ NPs (Figure S3). We also tested the effect of varying the extracellular calcium concentration in the culture medium of HEKn. According to this protocol, we induced the keratinocyte differentiation by increasing by a factor of 20 , the extracellular calcium concentration in the culture medium $(1.2 \mathrm{mM})$. We then performed $\mu$-PIXE analysis to measure the intracellular content of titanium and calcium after 20 hours of exposure of the different $\mathrm{TiO}_{2}$ NPs. As illustrated in Figure S4, the control cells showed similar intracellular calcium contents (around $0.1+/-0.02 \mu \mathrm{g} . \mathrm{cm}^{-2}$ ) no matter the calcium concentrations in culture media. In high calcium condition, HEKn cells exhibited the same intracellular calcium concentration whether they were exposed or not to NPs (Table S2). When exposed, their internal titanium content remains very low (ranging from 0 to $0.04 \mu \mathrm{g} . \mathrm{cm}^{-2}$, for TNs and INPs, respectively) and in the same range whatever the NPs type (Figure S4 and Table S2). This suggests that the regulation of the cellular calcium metabolism is not impaired in differentiated HEKn cells (they remain able to control the calcium efflux between their extra- and intracellular compartments) and that HEKn are far less permeable to $\mathrm{TiO}_{2}$ NPs internalization than HUVEC.

The fact that the titanium intracellular content in differentiated HEKn is lower than in the proliferating cells and independent of the type of NPs could suggest a role of the cellular function with regards to a potential sensitivity to $\mathrm{TiO}_{2}$ NPs uptake and the 
subsequent toxicity issues. To confirm this observation, we exposed the undifferentiated HEKn (low-calcium medium) to a higher dose of $\mathrm{TiO}_{2} \mathrm{NPs}\left(10 \mu \mathrm{g} . \mathrm{cm}^{-2}\right)$, and measured the resulting titanium intracellular content (Figure 3). This set of experiments showed that even at doses as high as $10 \mu \mathrm{g} \cdot \mathrm{cm}^{-2}$ (incubation for 20 hours), the intracellular uptake of titanium remains independent of the external concentration and coherent with the observations made at $2 \mu \mathrm{g} \cdot \mathrm{cm}^{-2}$ (Table S2). Moreover, the intracellular contents for both calcium and iron, were elevated with positive correlation for NNs, which are the most internalized in the HEKn cells. It is also interesting to note that the content of iron was also elevated in this condition. EpiLife ${ }^{\circledR}$ contains ferric sulfate $\left(\mathrm{Fe}_{2}\left(\mathrm{SO}_{4}\right)_{3}-7 \mathrm{H}_{2} \mathrm{O}\right)$ and calcium chloride $\left(\mathrm{CaCl}_{2}-2 \mathrm{H}_{2} \mathrm{O}\right)$. This observation could suggest that $\mathrm{TiO}_{2} \mathrm{NPs}$ favor (i) the internalization of free positively-charged ions in the intracellular compartment, (ii) ionic homeostasis modifications and the subsequent metabolic consequences (cell stress, cell differentiation, cell death)

\section{$\mathrm{TiO}_{2} \mathrm{NPs}$ internalization induced marked ER stress}

$\mathrm{TiO}_{2}$ NPs induced a clear disruption of the calcium homeostasis, itself related to many of stress pathways (ROS, ER stress) (Jacobson and Duchen 2002, Djurišić et al. 2015). To better characterize the influences of $\mathrm{TiO}_{2}$ NPs on these different stress pathways, selected target gene expression was examined by Real Time quantitative Polymerase Chain Reaction (RT-qPCR) assay (Higa et al. 2014). HUVEC cells were exposed to 2 $\mu \mathrm{g} . \mathrm{cm}^{-2}$ of the diverse types of $\mathrm{TiO}_{2}$ NPs for 20 hours. Total RNA was extracted and analyzed using RT-qPCR. The expression analysis was performed using both hGAPDH and $h 18 S$, as internal standards. 
ROS pathway

SOD1, SOD2, CAT1, CAT2, GPX expression were tested. Gene expression analysis revealed some differences between controls and exposed HUVEC cells No difference was found for the superoxide dismutase1 (SOD1), the catalases (CAT1 and 2) or the glutathione peroxidase (GPX1). However, after 6 hours of NPs exposure, the expression level of SOD2 was significantly increased and depended on the type of NPs (10 times higher in the presence of TNs, and 2 to 4 times when incubated with INPs and P25). This suggested that the ROS production in the presence of $\mathrm{TiO}_{2} \mathrm{NPs}$ may preferentially be associated to mitochondrial dysfunction.

\section{Mitochondria}

As the ROS pathway analysis pointed towards the mitochondria as a site potentially affected by $\mathrm{TiO}_{2} \mathrm{NPs}$, we evaluated the mitochondrial membrane potential $(\Delta \Psi \mathrm{m})$ using Tetramethylrhodamine Methyl Ester (TMRM). Untreated cells exhibited a homogenous and intense labeling of their mitochondrial network at both single cell and cell population levels. By contrast, after their exposure to $\mathrm{TiO}_{2} \mathrm{NPs}$, TMRM labeling was diffuse, heterogeneous and weak (Figure 5a and 5b). This observation corroborates marked mitochondrial and metabolic dysfunctions in relation to the presence of the $\mathrm{TiO}_{2}$ NPs. Moreover, as TMRM is also an indicator of cell death, this observation is in agreement with our previous findings on cell proliferation and toxicity.

To confirm this observation between $\mathrm{TiO}_{2}$ NPs toxicity and mitochondrial dysfunction, we also performed TEM analysis on both HUVEC and HeLa exposed to $\mathrm{TiO}_{2}$ NPs with $2 \mu \mathrm{g} . \mathrm{cm}^{-}{ }^{2}$ for several hours and confirmed the micro-structural alterations of mitochondria in the vicinity of internalized $\mathrm{TiO}_{2} \mathrm{NPs}$ aggregates (Figure 5c-f). These alterations correspond mainly to a mitochondrial membrane disruption and 
internal matrix disorganization. Taken together, these results showed that $\mathrm{TiO}_{2} \mathrm{NPs}$ induced (i) calcium homeostasis alteration, (ii) moderate ROS production and (iii) mitochondrial dysfunction.

\section{ER stress}

The expression of chop, Erdj4, Herpud1 was quantified in HUVEC cells exposed to different types of $\mathrm{TiO}_{2}$ NPs $\left(2 \mu \mathrm{g} . \mathrm{cm}^{-2}\right)$ in a time course mode using RT-qPCR (Figure 6a). Correlation between the time-response and the level of expression of the selected genes was strongly dependent on the nature of $\mathrm{TiO}_{2} \mathrm{NPs}$ and therefore on their level of toxicity. Indeed the most toxic TNs (cell proliferation threshold to zero for the smallest content of titanium per cell) induced the expression of DDIT3/chop, Erdj4, Herpud1after only 2 hours of exposure ( $>30$ fold for DDIT3/chop) and maintained upregulated during the following 20 hours. By contrast, for NNs, which are scarcely internalized in HUVEC cells, the expression level of these 3 genes exhibited very little change. Moderate and time-dependent increases of expression levels were observed for the cells incubated with P25 and INPs ( $>8$ fold for DDIT3/chop, 4 hours after incubation). Despite their higher content in the cells as compared to TNs, they showed less detrimental consequences, phenomenon likely to be attributable to their lower surface area and the scrolled structure of the TNs, which allows a higher interface with the environment. In addition, this positive correlation between the level of $\mathrm{TiO}_{2} \mathrm{NPs}$ toxicity and the expression of ER stress markers at the RNA level was confirmed at the protein levels by the presence of nuclear CHOP in exposed cells (Figure 6 d-e). CHOP protein is expressed in ER stressed cells and reveals a restricted nuclear localization. CHOP induces a cell cycle stop in G1/S (Ron and Habener 1992, Vittoria Barone et al. 1994). 


\section{Discussion}

$\mathrm{TiO}_{2}$ NPs are widely used, produced in diverse shapes, but it remains largely unknown how modification of the $\mathrm{TiO}_{2}$ NPs morphology (size, geometry...) may alter their bioavailability, their effects on biological systems and the resultant in vitro and in vivo toxicity. In particular, the behavior of NPs inside living cells is still an enigma, and no metabolic responses induced by $\mathrm{TiO}_{2}$ NPs have been fully identified so far. To answer this question, we developed an interdisciplinary approach (combining biophysics, analytical chemistry, nanochemistry, cellular and molecular biology) to outline the cellular mechanisms that linked the bioaccumulation and the in vitro toxicity of diverse morphologies of $\mathrm{TiO}_{2} \mathrm{NPs}$.

We established a strong correlation between the rate of internalized titanium and (i) the intracellular calcium content and (ii) a specific metabolic pathway: ER stress. $\mathrm{TiO}_{2}$ NPs exhibit different toxicity levels strongly depending not only on their morphologies (size, shape) and their related behavior in biological media, but also on the considered cellular type.

According to our observations, $\mathrm{TiO}_{2}$ NPs impact on cell proliferation/viability not only depends on the dose and on the morphology of NPs but also on the cell type. Indeed, P25, INPs and TNs dramatically affected proliferation, whereas NNs were harmless in HUVEC cells. On the contrary, in HEKn, proliferation assays indicated that P25, NNs, and INPs exhibited a moderate dose-dependent toxicity even after several days. To explain the toxicity disparity observed for the different NPs, different hypotheses can be made among which: (i) the aggregation states of the $\mathrm{TiO}_{2} \mathrm{NPs}$ in the different media, (ii) a specific shape-induced chemistry. For example, TNs are far from being well-identified objects but exhibit a structure made of parallel-corrugated ribbons 
of edge-sharing $\mathrm{TiO}_{6}$ octahedra. This scrolled nanosheet structure results in some local structural variations, such as changes of the Ti-O bond lengths and bond angles in the octahedra, which are then more distorted and more reactive. These scrolled nanosheets exhibit as well a much larger surface area than the other well-crystallized NPs increasing the exchanges with cell membranes and the intracellular medium (Gao et al. 2009).

A third hypothesis is that the toxicity is determined by the effective content of titanium that each cell type is susceptible to internalize and not directly correlated with the exposure concentration. Indeed, the aggregation states of the $\mathrm{TiO}_{2} \mathrm{NPs}$ changed in the different culture media what could modify the deposition rate of the NPs and the real delivered doses as illustrated further on and previously discussed in the literature (Cohen et al. 2013, 2014, Deloid et al. 2014, Pal et al. 2016). One challenge in nanotoxicology is to quantify the real dose of exposure within a cell. Indeed, the use of mass concentration commonly used to assess bulk material toxicity or either the exposure dose in toxicology studies are not appropriate to nanotoxicology evaluation (Zhao et al. 2013). Here, we assess the intracellular quantity of $\mathrm{TiO}_{2}$ nanoparticles at the single cell level using $\mu$-PIXE analysis.

We have shown that the intracellular content of titanium is heterogeneous from one cell to another and is dependent on both the NPs morphologies, and the cell type. This result corroborates a previous in silico study which showed that the internalization rate of NPs can be modified by a 60-fold factor as a function of the NPs shape (Nangia and Sureshkumar 2012). Moreover, an in vivo study confirmed this observation showing that different shapes of silica NPs differentially altered physiological functions in exposed rats (Li et al. 2015). 
Furthermore, we previously showed that P25 internalization in keratinocytes induced an elevated and related accumulation of intracellular calcium (Simon et al. 2011). Here, we confirmed and generalized this observation to the other morphologies of $\mathrm{TiO}_{2} \mathrm{NPs}$ and to two other primary cell types (HUVEC and HEKn).

We also showed that a minimal intracellular content of titanium is necessary and mandatory to induce a marked calcium homeostasis alteration, which is also cell-type dependent. In addition, intracellular calcium homeostasis is constantly found correlated to the intracellular titanium content (independently of the extracellular calcium content). Even if this phenomenon has been previously evidenced by different methods (Koeneman et al. 2010, Simon et al. 2011), the subsequent consequences for the cells remain to be clearly identified and correlated (or not) with NPs-mediated toxicity. Potential explanations are as follows (i) $\mathrm{TiO}_{2} \mathrm{NPs}$ are negatively charged in culture media (physiological $\mathrm{pH}$ ) and thus can fix calcium ions on their surface when entering the cell, or (ii) that $\mathrm{TiO}_{2}$ entry in cells could induce biological pathways modifying the calcium influx.

Calcium is known to be a key modulator of fundamental processes involving mitochondria, the ER stress and the regulation of major metabolic pathways such as proliferation, differentiation (for example for keratinocytes), inflammation, necrosis/apoptosis.

Previous studies reported ROS pathway as a key player in NPs toxicity response (reviewed in Djurišić et al. 2015). In this study, we observed a minor change in the ROS metabolism (as a supposed result of a mitochondrial dysfunction) and suggested that $\mathrm{TiO}_{2}$ NPs toxicity was not primarily induced by this pathway.

Previous data suggested that $\mathrm{TiO}_{2}$ NPs (P25) internalization was linked to ER stress apparition in human bronchial epithelial cells (16HBE140-) and in HUVEC 
(Zhang et al. 2012, Chen et al. 2014, Yu, Chang, et al. 2015). Our data show that the internalization of titanium ( $\left.\mathrm{TiO}_{2} \mathrm{NPs}\right)$, besides increasing the cell calcium content, does also induce the expression of CHOP (ATF4 pathway) and activates (i) the ER stress in HUVEC cells and (ii) differentiation in keratinocytes. In addition, ER stress and disruption of cellular calcium homeostasis are strongly associated with mitochondrial dysfunction (Zhang et al. 2012). Here, we show that this mitochondrial alteration is effective for a minimal content of $\mathrm{TiO}_{2}$ NPs defining here the level of toxicity. Our results also bring out further information on these processes because they provide a quantitative analysis of these phenomena (including dose threshold), stressing not only on the effective quantity of exogenous element internalized in individual cells but also on the dose the cells have been exposed to. These two parameters, ER stress and intracellular calcium concentration, should be considered as cardinal and early markers of the in vitro toxicity evaluation not only of $\mathrm{TiO}_{2} \mathrm{NPs}$, but also of other metal oxide nanoparticles. These results (minimal threshold to induce toxicity and the resulting cellular responses) are summarized in Figure S5. $\mathrm{As} \mathrm{TiO}_{2} \mathrm{NPs}$ are able to cross natural barriers such as the intestine and the blood-brain barrier, these markers should also to be taken in consideration to evaluate the in vivo nanotoxicity of NPs (Yamashita et al. 2011, Brun et al. 2012, Setyawati et al. 2013, Setyawati, Tay, Docter, et al. 2015).

Ultimately, the present results indicate that the ATF4 pathway (induction of CHOP expression) is activated in HUVEC cells confirming the strong link between the level of $\mathrm{TiO}_{2}$ NPs toxicity (which is also shape dependent), the intracellular titanium and calcium contents, the ER stress induction and mitochondrial alterations. We show that these different parameters give rise to the establishment of a level of toxicity based on the morphology in between the different $\mathrm{TiO}_{2} \mathrm{NPs}$; the TNs presenting the highest level of toxicity (the lowest proliferation rate for the smallest internalized rate). 


\section{Conclusion}

We showed that $\mathrm{TiO}_{2}$ NPs are internalized at various degrees and their toxicity depends (i) on titanium content and nanoparticle shape, which impact on intracellular calcium homeostasis thereby leading to endoplasmic reticulum stress for a given cell line and (ii) on the considered cell type. Lastly, we showed that a minimal intracellular content of titanium is mandatory to induce detectable toxicity enlightening once more the crucial notion of internalized dose threshold beside the well-recognized dose of exposure. Our research highlights the understanding of the toxic effect induced by $\mathrm{TiO}_{2}$ NPs according to their bioavailability and behavior in biological media. We also stress the central role played by the ER stress and the intracellular calcium homeostasis as molecular sensors of the NPs toxicity detection. 


\section{Acknowledgements}

This research was undertaken on the high-resolution microbeam line at the AIFIRA facility (“Applications Interdisciplinaires des Faisceaux d'Ions en Région Aquitaine”). We also wish to thank the technical staff members of the AIFIRA facility ( $\mathrm{Ph}$. Alfaurt, S. Sorieul), the Bordeaux Imaging Center (TEM facility, E. Gontier and M. Petrel). The Région Aquitaine supported financially the AIFIRA facility and the technical development of the microbeam line. The authors acknowledge the Evonik (Degussa) Company (Düsseldorf, Germany) for their generous gift ( $\mathrm{P} 25 \mathrm{TiO}_{2} \mathrm{NPs}$ ). This work has been partly supported by the European Community as an Integrating Activity "Support of Public and Industrial Research Using Ion Beam Technology" (SPIRIT) under the EC contract $\mathrm{n}^{\circ} 227012$ and as an "Integrating Activity Supporting Postgraduate Research with Internships in Industry and Training Excellence" (SPRITE) under EC contract no. 317169. The CNRS, the French National Research Agency (ANR CES2010, ${ }^{\circ}$ CESA 009 01, TITANIUMS) and the Région Aquitaine (TOX-NANO n 20111201003 / POPRA n $\left.{ }^{\circ} 14006636-034\right)$ support the research program and the funding of QLT, GS, GM, MS.

The manuscript was written through contributions of all authors. All authors have given approval to the final version of the manuscript. The author wish it to be known, in their opinion, the first two authors (MS, GS) should be regarded as joint First Authors ( $\$$ ).

\section{Disclosure of interest}

The authors report no conflicts of interest.

\section{Supporting Information}

Tables S1 and S2: Quantitative summary of the intracellular contents in calcium and titanium in HEKn and HUVEC. Table S3 contains the RTqPCR primers list used in this work. Figure S1 summarizes the $\mathrm{TiO}_{2}$ NPs behavior in different biological media (hydrodynamic diameter variation). Figure S2 summarizes the dose-response effect on human cell culture proliferation in respect to the $\mathrm{TiO}_{2}$ NPs morphologies and to the cell type (HUVEC, HeLa). Figure S3 shows the relation between intracellular titanium content and other intracellular chemical elements such as iron and calcium. Supporting Information is available from the Wiley Online Library or from the author. 


\section{References}

Bhattacharya, K., Davoren, M., Boertz, J., Schins, R.P., Hoffmann, E., and Dopp, E., 2009. Titanium dioxide nanoparticles induce oxidative stress and DNA-adduct formation but not DNA-breakage in human lung cells. Particle and Fibre Toxicology, $6(1), 17$.

Brun, E., Carrière, M., and Mabondzo, A., 2012. In vitro evidence of dysregulation of blood-brain barrier function after acute and repeated/long-term exposure to $\mathrm{TiO} 2$ nanoparticles. Biomaterials, 33 (3), 886-896.

Cai, K., Hou, Y., Hu, Y., Zhao, L., Luo, Z., Shi, Y., Lai, M., Yang, W., and Liu, P., 2011. Correlation of the cytotoxicity of TiO 2 nanoparticles with different particle sizes on a sub-200-nm scale. Small, 7 (21), 3026-3031.

Chen, R., Huo, L., Shi, X., Bai, R., Zhang, Z., Zhao, Y., Chang, Y., and Al, C.E.T., 2014. Endoplasmic Reticulum Stress Induced by Zinc Oxide Nanoparticles Is an Earlier Biomarker for Nanotoxicological Evaluation. ACS nano, 8 (3), 2562-2574.

Chen, X. and Mao, S.S., 2007. Titanium dioxide nanomaterials: Synthesis, properties, modifications and applications. Chemical Reviews, 107 (7), 2891-2959.

Cohen, J., Deloid, G., Pyrgiotakis, G., and Demokritou, P., 2013. Interactions of engineered nanomaterials in physiological media and implications for in vitro dosimetry, 7 (February 2012), 417-431.

Cohen, J.M., Teeguarden, J.G., and Demokritou, P., 2014. An integrated approach for the in vitro dosimetry of engineered nanomaterials, $1-12$.

Deloid, G., Cohen, J.M., Darrah, T., Derk, R., Rojanasakul, L., Pyrgiotakis, G., Wohlleben, W., and Demokritou, P., 2014. nanomaterials for in vitro dosimetry. Nature Communications, 5, 1-10.

Devan, R.S., Patil, R.A., Lin, J.-H., and Ma, Y.-R., 2012. One-Dimensional MetalOxide Nanostructures: Recent Developments in Synthesis, Characterization, and Applications. Advanced Functional Materials, 22 (16), 3326-3370.

Devès, G., Cohen-Bouhacina, T., and Ortega, R., 2004. Scanning transmission ion microscopy mass measurements for quantitative trace element analysis within biological samples and validation using atomic force microscopy thickness measurements. Spectrochimica Acta Part B: Atomic Spectroscopy, 59 (10-11), 
$1733-1738$.

Djurišić, A.B., Leung, Y.H., Ng, A.M.C., Xu, X.Y., Lee, P.K.H., Degger, N., and Wu, R.S.S., 2015. Toxicity of metal oxide nanoparticles: Mechanisms, characterization, and avoiding experimental artefacts. Small, 11 (1), 26-44.

Donaldson, K., Stone, V., Clouter, A., Renwick, L., and MacNee, W., 2001. Ultrafine particles. Occup Environ Med, 58 (3), 211.

Federici, G., Shaw, B.J., and Handy, R.D., 2007. Toxicity of titanium dioxide nanoparticles to rainbow trout (Oncorhynchus mykiss): Gill injury, oxidative stress, and other physiological effects. Aquatic Toxicology, 84 (4), 415-430.

Gao, T., Fjellvåg, H., and Norby, P., 2009. Crystal structures of titanate nanotubes: A Raman scattering study. Inorganic Chemistry, 48 (4), 1423-1432

Geiser, M., Rothen-Rutishauser, B., Kapp, N., Schürch, S., Kreyling, W., Schulz, H., Semmler, M., Hof, V.I., Heyder, J., and Gehr, P., 2005. Ultrafine Particles Cross Cellular Membranes by Nonphagocytic Mechanisms in Lungs and in Cultured Cells. Environmental Health Perspectives, 113 (11), 1555-1560.

Hamilton, R.F., Wu, N., Porter, D., Buford, M., Wôlfarth, M., and Holian, A., 2009. Particle length-dependent titanium dioxide nanomaterials toxicity and bioactivity. Particle and fibre toxicology, 6, 35.

Higa, A., Taouji, S., Lhomond, S., Jensen, D., Fernandez-Zapico, M.E., Simpson, J.C., Pasquet, J.-M., Schekman, R., and Chevet, E., 2014. Endoplasmic reticulum stressactivated transcription factor ATF6 $\alpha$ requires the disulfide isomerase PDIA5 to modulate chemoresistance. Molecular and cellular biology, 34 (10), 1839-49.

Jacobson, J. and Duchen, M.R., 2002. Mitochondrial oxidative stress and cell death in astrocytes -- requirement for stored $\mathrm{Ca} 2+$ and sustained opening of the permeability transition pore. J Cell Sci, 115 (6), 1175-1188.

Jovanovic, B., 2015. Review of titanium dioxide nanoparticle phototoxicity: Developing a phototoxicity ratio to correct the endpoint values of toxicity tests. Environmental Toxicology and Chemistry, 34 (5), 1070-1077.

Kaegi, R., Ulrich, a., Sinnet, B., Vonbank, R., Wichser, a., Zuleeg, S., Simmler, H., Brunner, S., Vonmont, H., Burkhardt, M., and Boller, M., 2008. Synthetic TiO2 nanoparticle emission from exterior facades into the aquatic environment. 
Environmental Pollution, 156 (2), 233-239.

Kahru, A. and Dubourguier, H.C., 2010. From ecotoxicology to nanoecotoxicology. Toxicology, 269 (2-3), 105-119.

Kasuga, T., 2006. Formation of titanium oxide nanotubes using chemical treatments and their characteristic properties. Thin Solid Films, 496 (1), 141-145.

Koeneman, B.A., Zhang, Y., Westerhoff, P., Chen, Y., Crittenden, J.C., and Capco, D.G., 2010. Toxicity and cellular responses of intestinal cells exposed to titanium dioxide. Cell Biol Toxicol, 26, 225-238.

Lai, J.C.K., Lai, M.B., Jandhyam, S., Dukhande, V. V., Bhushan, A., Daniels, C.K., and Leung, S.W., 2008. Exposure to titanium dioxide and other metallic oxide nanoparticles induces cytotoxicity on human neural cells and fibroblasts. International Journal of Nanomedicine, 3 (4), 533-545.

Lee, J., Mahendra, S., and Alvarez, P.J.J., 2010. Nanomaterials in the Construction Industry: A Review of Their Applications. ACS nano, 4 (7), 3580-3590.

Lewinski, N., Colvin, V., and Drezek, R., 2008. Cytotoxicity of Nanoparticles. Small, 4 (1), 26-49.

Li, L., Liu, T., Fu, C., Tan, L., Meng, X., and Liu, H., 2015. Biodistribution, excretion, and toxicity of mesoporous silica nanoparticles after oral administration depend on their shape. Nanomedicine: Nanotechnology, Biology, and Medicine, 11 (8), 19151924.

Li, Q., Mahendra, S., Lyon, D.Y., Brunet, L., Liga, M. V., Li, D., and Alvarez, P.J.J., 2008. Antimicrobial nanomaterials for water disinfection and microbial control: Potential applications and implications. Water Research, 42 (18), 4591-4602.

Liang, Y.T., Vijayan, B.K., Lyandres, O., Gray, K. a., and Hersam, M.C., 2012. Effect of dimensionality on the photocatalytic behavior of carbon-titania nanosheet composites: Charge transfer at nanomaterial interfaces. Journal of Physical Chemistry Letters, 3 (13), 1760-1765.

Long, T.C., Saleh, N., Tilton, R.D., Lowry, G. V, and Veronesi, B., 2006. Titanium Dioxide ( P25 ) Produces Reactive Oxygen Species in Immortalized Brain Microglia ( BV2 ): Implications for Nanoparticle. Environ. Sci. \& Technolo, 7-13. 
Nangia, S. and Sureshkumar, R., 2012. Efects of nanoparticle charge and shape anisotropy on traslocation through cell membranes. Langmuir, 28 (51), 1766.

Nian, J.N. and Teng, H., 2006. Hydrothermal synthesis of single-crystalline anatase TiO2 nanorods with nanotubes as the precursor. Journal of Physical Chemistry B, $110(9), 4193-4198$.

Oberdorster, G., Ferin, J., and Lehnert, B.E., 1994. Correlation between particle size, in vivo particle persistence, and lung injury. Environmental Health Perspectives, 102 (SUPPL. 5), 173-179.

Oesch, F. and Landsiedel, R., 2012. Genotoxicity investigations on nanomaterials. Arch Toxicol, (86), 985-994.

Osano, E., Kishi, J., and Takahashi, Y., 2003. Phagocytosis of titanium particles and necrosis in TNF-??-resistant mouse sarcoma L929 cells. Toxicology in Vitro, 17 (1), 41-47.

Pal, A.K., Bello, D., Cohen, J., Demokritou, P., and Program, B., 2016. HHS Public Access, 9 (7), 871-885.

Rahman, Q., Lohani, M., Dopp, E., Pemsel, H., Jonas, L., Weiss, D.G., and Schiffmann, D., 2002. Evidence that ultrafine titanium dioxide induces micronuclei and apoptosis in syrian hamster embryo fibroblasts. Environmental Health Perspectives, 110 (8), 797-800.

Ron, D. and Habener, J.F., 1992. CHOP, a novel develpomentally regulated nuclear protein that dimerizes with the transcription factors C/EBP and LAP and functions as a dominant negative regulator of gene transcription. Genes Dev, 6, 439.

Sadrieh, N., Wokovich, A.M., Gopee, N. V, Zheng, J., Haines, D., Parmiter, D., Siitonen, P.H., Cozart, C.R., Patri, A.K., Mcneil, S.E., Howard, P.C., Doub, W.H., and Buhse, L.F., 2010. Lack of Significant Dermal Penetration of Titanium Dioxide from Sunscreen Formulations Containing Nano- and Submicron-Size TiO2 Particles. Toxicological Sciences, 115 (1), 156-166.

Sager, T.M., Kommineni, C., and Castranova, V., 2008. Pulmonary response to intratracheal instillation of ultrafine versus fine titanium dioxide: role of particle surface area. Particle and Fibre Toxicology, 5 (1), 17.

Sayes, C.M., Wahi, R., Kurian, P.A., Liu, Y., West, J.L., Ausman, K.D., Warheit, D.B., 
and Colvin, V.L., 2006. Correlating nanoscale titania structure with toxicity: A cytotoxicity and inflammatory response study with human dermal fibroblasts and human lung epithelial cells. Toxicological Sciences, 92 (1), 174-185.

Schwartzenberg, K.C. and Gray, K.A., 2012. Nanostructured Titania: the current and future promise of Titania nanotubes. Catalysis Science \& Technology, 2 (8), 1617.

Setyawati, M.I., Tay, C.Y., Chia, S.L., Goh, S.L., Fang, W., Neo, M.J., Chong, H.C., Tan, S.M., Loo, S.C.J., Ng, K.W., Xie, J.P., Ong, C.N., Tan, N.S., and Leong, D.T., 2013. Titanium dioxide nanomaterials cause endothelial cell leakiness by disrupting the homophilic interaction of VE-cadherin. Nature communications, 4, 1673.

Setyawati, M.I., Tay, C.Y., Docter, D., Stauber, R.H., and Leong, D.T., 2015. Understanding and exploiting nanoparticles' intimacy with the blood vessel and blood. Chemical Society reviews, 44 (22), 8174-99.

Setyawati, M.I., Tay, C.Y., and Leong, D.T., 2015. Mechanistic Investigation of the Biological Effects of $\mathrm{SiO} 2, \mathrm{TiO} 2$, and $\mathrm{ZnO}$ Nanoparticles on Intestinal Cells. Small, 11 (28), 3458-3468.

Simon, M., Barberet, P., Delville, M.-H., Moretto, P., and Seznec, H., 2011. Titanium dioxide nanoparticles induced intracellular calcium homeostasis modification in primary human keratinocytes. Towards an in vitro explanation of titanium dioxide nanoparticles toxicity. Nanotoxicology, 5 (2), 125-39.

Sugimoto, T., Zhou, X., and Muramatsu, A., 2003. Synthesis of uniform anatase TiO2 nanoparticles by gel - sol method 3. Formation process and size control. Journal of Colloid and Interface Science, 259, 43-52.

Sun, Q., Tan, D., Ze, Y., Sang, X., Liu, X., Gui, S., Cheng, Z., Cheng, J., Hu, R., Gao, G., Liu, G., Zhu, M., Zhao, X., Sheng, L., Wang, L., Tang, M., and Hong, F., 2012. Pulmotoxicological effects caused by long-term titanium dioxide nanoparticles exposure in mice. Journal of hazardous materials, 235-236, 47-53.

Tang, Y., Wang, F., Jin, C., Liang, H., Zhong, X., and Yang, Y., 2013. Mitochondrial injury induced by nanosized titanium dioxide in A549 cells and rats. Environmental Toxicology and Pharmacology, 36 (1), 66-72.

Tong, T., Shereef, A., Wu, J., Thi, C., Binh, T., Kelly, J.J., and Gray, K.A., 2013. E 
ffects of Material Morphology on the Phototoxicity of Nano-TiO2 to Bacteria. Envrionnemental Science \& Technology, 47, 12486-12495.

Toyooka, T., Amano, T., and Ibuki, Y., 2012. Titanium dioxide particles phosphorylate histone H2AX independent of ROS production. Mutation Research/Genetic Toxicology and Environmental Mutagenesis, 742 (1-2), 84-91.

Le Trequesser, Q., Devès, G., Saez, G., Daudin, L., Barberet, P., Michelet, C., Delville, M.-H., and Seznec, H., 2014. Single cell in situ detection and quantification of metal oxide nanoparticles using multimodal correlative microscopy. Analytical chemistry, 86 (15), 7311-9.

Vevers, W.F. and Jha, A.N., 2008. Genotoxic and cytotoxic potential of titanium dioxide (TiO2) nanoparticles on fish cells in vitro. Ecotoxicology, 17 (5), 410-420.

Vittoria Barone, M., Crozat, A., Tabaee, A., Philipson, L., and Ron, D., 1994. CHOP (GADD153) and its oncogenic variant, TLS-CHOP, have opposing effects on the induction of G1/S arrest. Genes and Development, 8 (4), 453-464.

Wang, J.J., Sanderson, B.J.S., and Wang, H., 2007. Cyto- and genotoxicity of ultrafine $\mathrm{TiO} 2$ particles in cultured human lymphoblastoid cells. Mutation Research Genetic Toxicology and Environmental Mutagenesis, 628 (2), 99-106.

Wang, Y., Chen, Z., Ba, T., Pu, J., Chen, T., Song, Y., Gu, Y., Qian, Q., Xu, Y., Xiang, K., Wang, H., and Jia, G., 2013. Susceptibility of young and adult rats to the oral toxicity of titanium dioxide nanoparticles. Small, 9 (9-10), 1742-1752.

Warheit, D.B., Webb, T.R., Reed, K.L., Frerichs, S., and Sayes, C.M., 2007. Pulmonary toxicity study in rats with three forms of ultrafine-TiO2 particles: Differential responses related to surface properties. Toxicology, 230 (1), 90-104.

Xia, T., Kovochich, M., Brant, J., Hotze, M., Sempf, J., Oberley, T., Sioutas, C., Yeh, J.I., Wiesner, M.R., and Nel, A.E., 2006. Comparison of the abilities of ambient and manufactured nanoparticles to induce cellular toxicity according to an oxidative stress paradigm. Nano Letters, 6 (8), 1794-1807.

Xia, Y., Yang, P., Sun, Y., Wu, Y., Mayers, B., Gates, B., Yin, Y., Kim, F., and Yan, H., 2003. One-Dimensional Nanostructures: Synthesis, Characterization, and Applications. Advanced Materials, 15 (5), 353-389.

Yamashita, K., Yoshioka, Y., Higashisaka, K., Mimura, K., Morishita, Y., Nozaki, M., 
Yoshida, T., Ogura, T., Nabeshi, H., Nagano, K., Abe, Y., Kamada, H., Monobe, Y., Imazawa, T., Aoshima, H., Shishido, K., Kawai, Y., Mayumi, T., Tsunoda, S.I., Itoh, N., Yoshikawa, T., Yanagihara, I., Saito, S., and Tsutsumi, Y., 2011. Silica and titanium dioxide nanoparticles cause pregnancy complications in mice. Nature nanotechnology, 6 (5), 321-328.

Yin, Z.F., Wu, L., Yang, H.G., and Su, Y.H., 2013. Recent progress in biomedical applications of titanium dioxide. Physical chemistry chemical physics, 15 (14), 4844-58.

Yu, J., Jaroniec, M., Yu, H., and Fan, W., 2012. Synthesis, characterization, properties, and applications of nanosized photocatalytic materials. Journal of Nanomaterials, 2012, 2-5.

Yu, K., Chang, S., Park, S.J., Lim, J., and Lee, J., 2015. Titanium Dioxide Nanoparticles Induce Endoplasmic Reticulum Stress-Mediated Autophagic Cell Death via Mitochondria- Associated Endoplasmic Reticulum Membrane Disruption in Normal Lung Cells. PLoS ONE, 1-17.

Yu, Z., Sun, Q., Pan, W., Li, N., and Tang, B., 2015. A Near-Infrared Triggered Nanophotosensitizer Inducing Domino E ff ect on Mitochondrial Reactive Oxygen Species Burst for Cancer Therapy. ACS nano, 9 (11), 11064-11074.

Zhang, R., Piao, M.J., Kim, K.C., Kim, A.D., Choi, J.Y., Choi, J., and Hyun, J.W., 2012. Endoplasmic reticulum stress signaling is involved in silver nanoparticlesinduced apoptosis. International Journal of Biochemistry and Cell Biology, 44 (1), 224-232.

Zhao, Y., Nel, A., and Riehemann, K., 2013. Filling knowledge gaps that distinguish the safety profiles of nano versus bulk materials. Small, 9 (9-10), 1426-1427.

Zhuang, M., Zheng, Y., Liu, Z., Huang, W., and Hu, X., 2015. Shape-dependent performance of $\mathrm{TiO}_{2}$ nanocrystals as adsorbents for methyl orange removal. RSC Adv., 5 (17), 13200-13207.

Zoroddu, M.A., Medici, S., Ledda, A., Nurchi, V.M., Lachowicz, J.I., and Peana, M., 2014. Toxicity of nanoparticles. Current medicinal chemistry, 21 (33), 3837-53. 


\section{Figures}

\section{Figure 1}

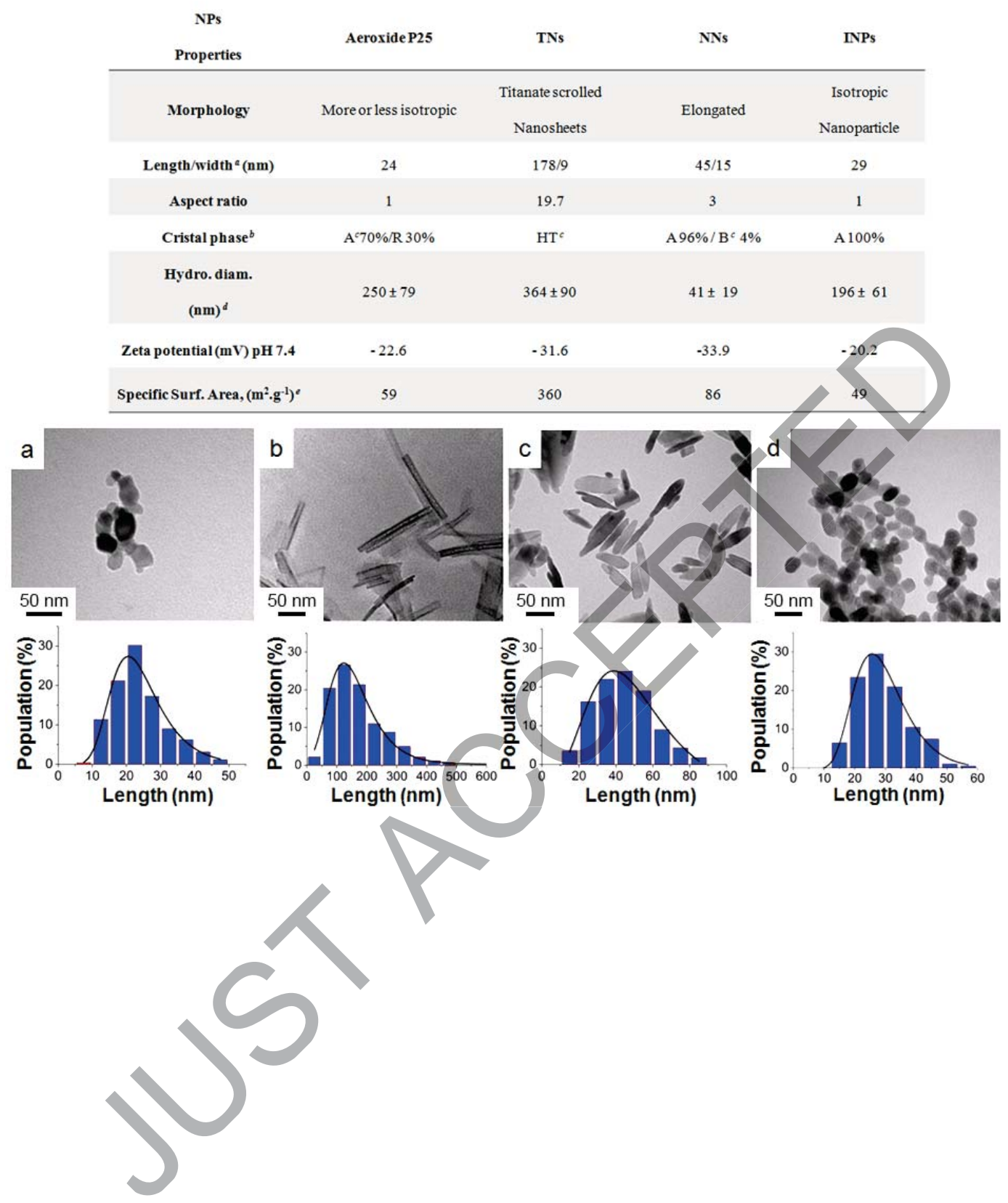


Figure 2

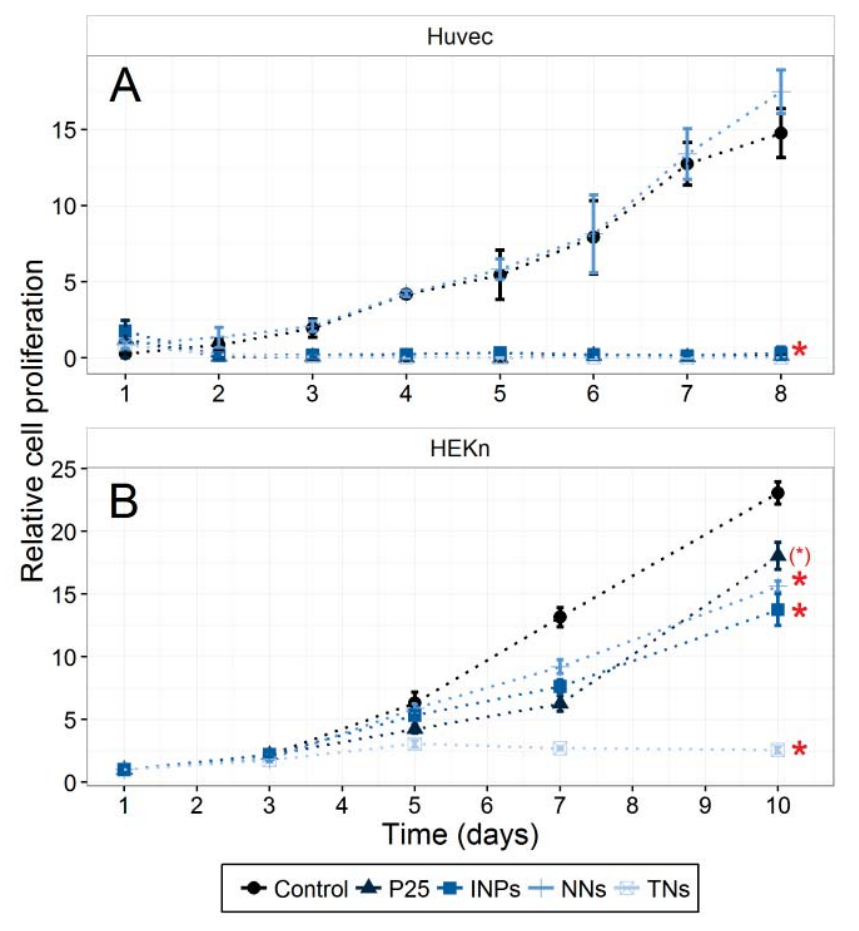


Figure 3

a

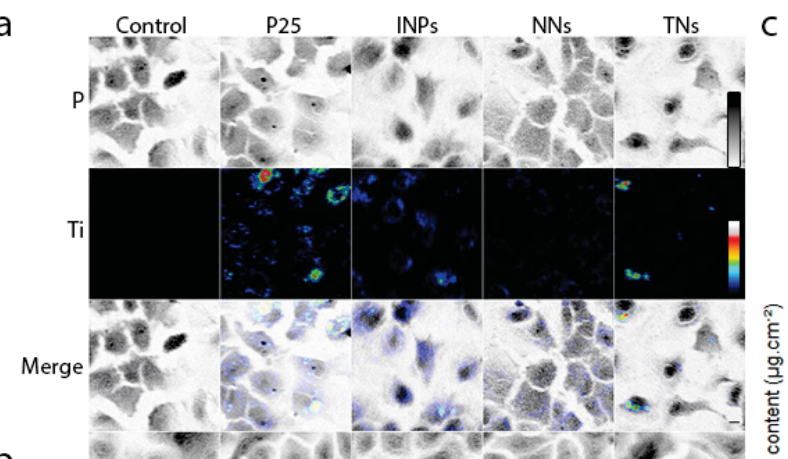

b
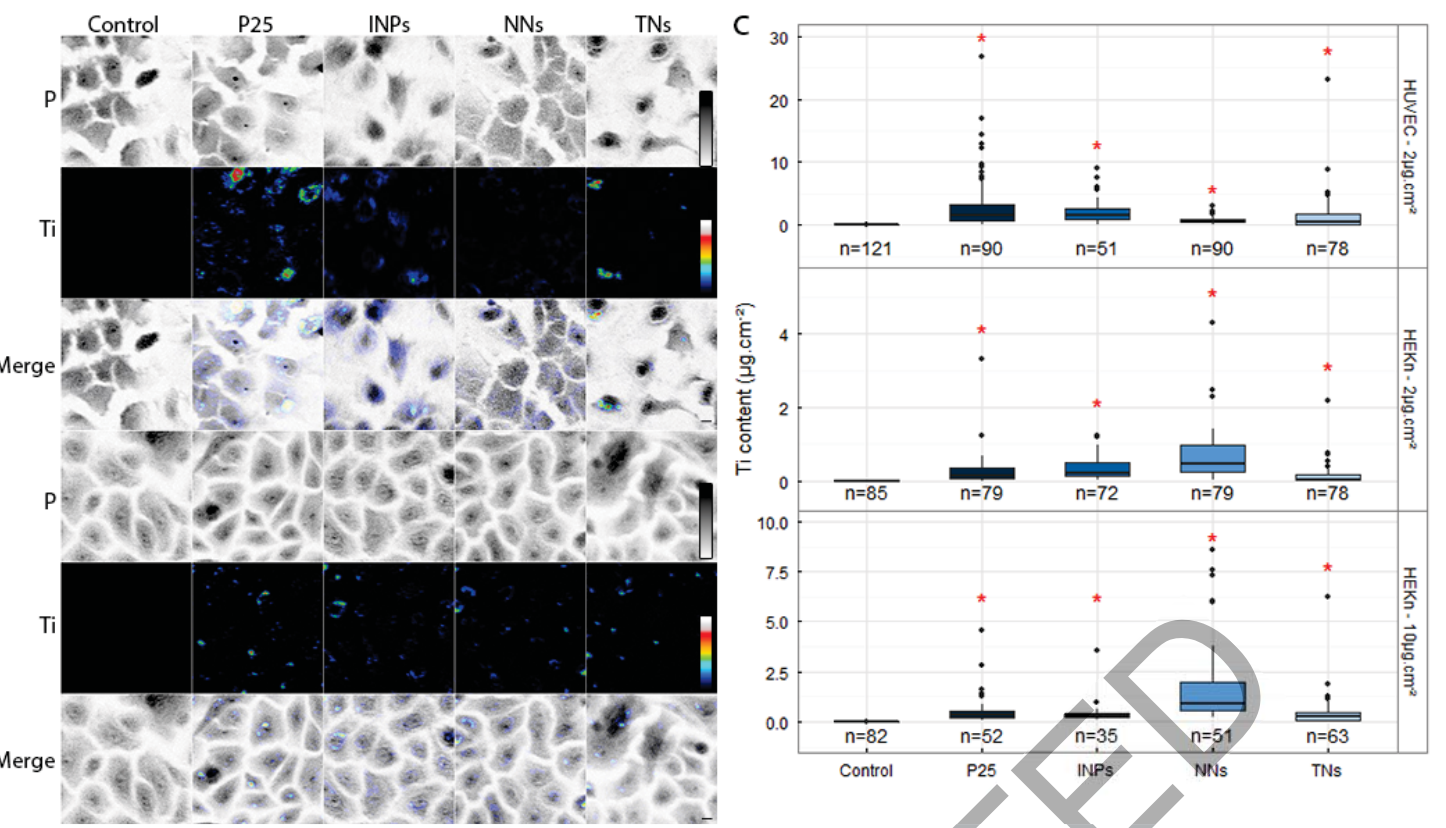
Figure 4

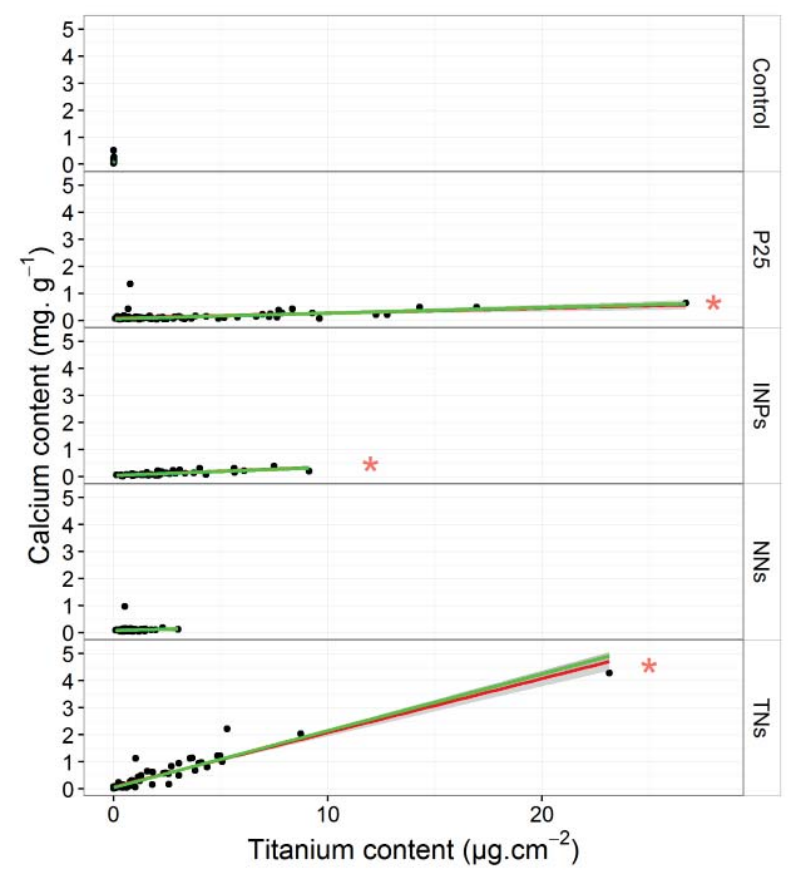


Figure 5

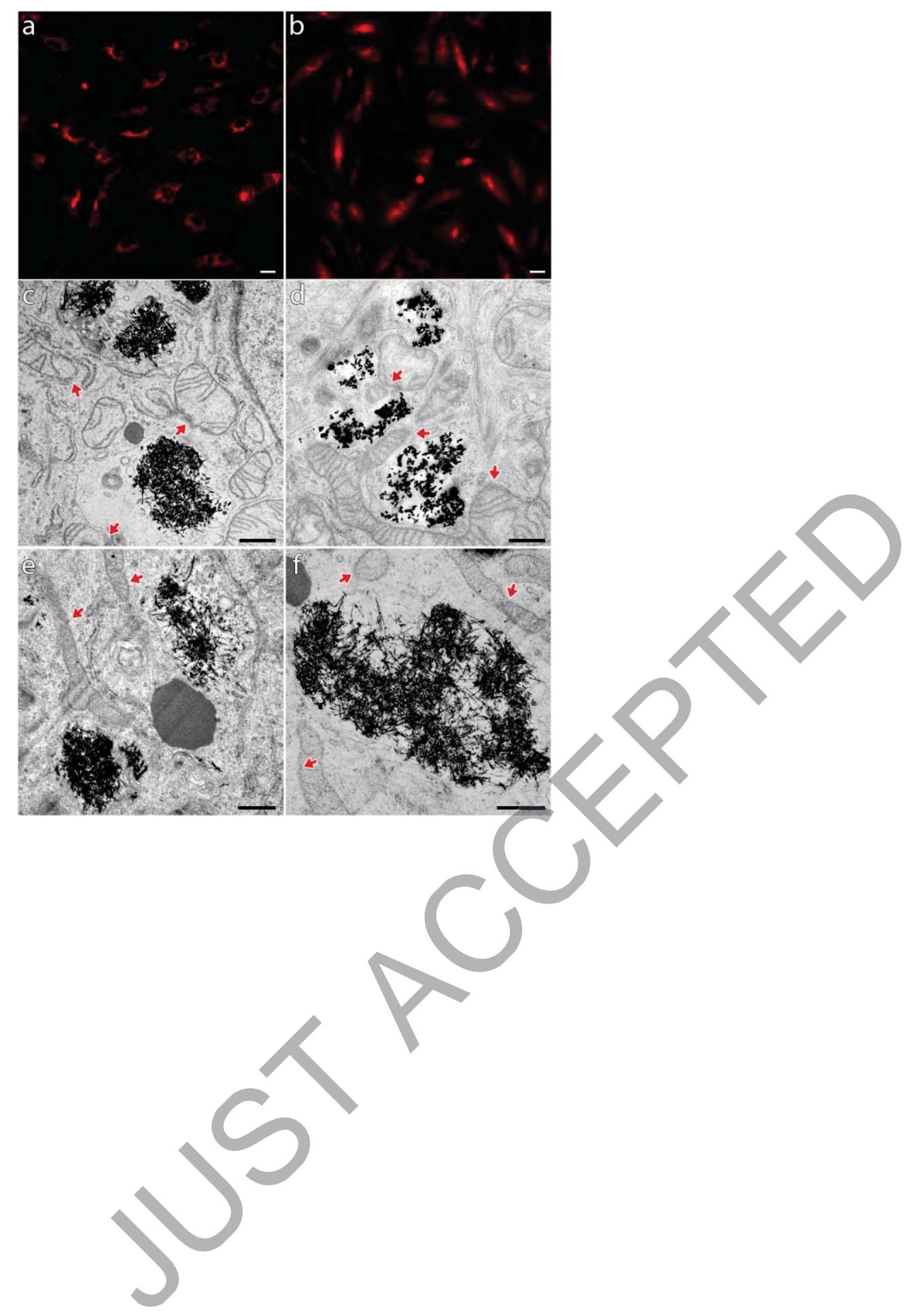


Figure 6

a

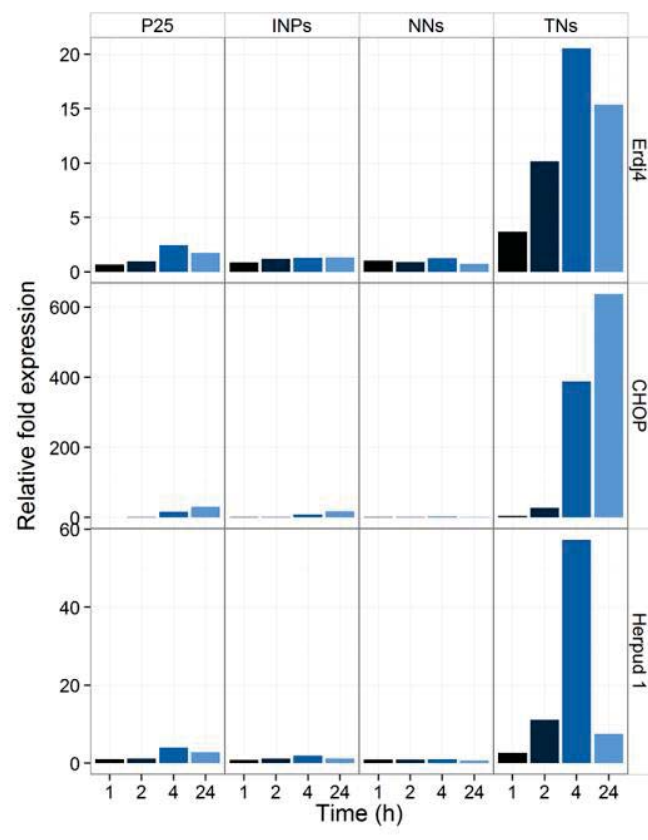

b
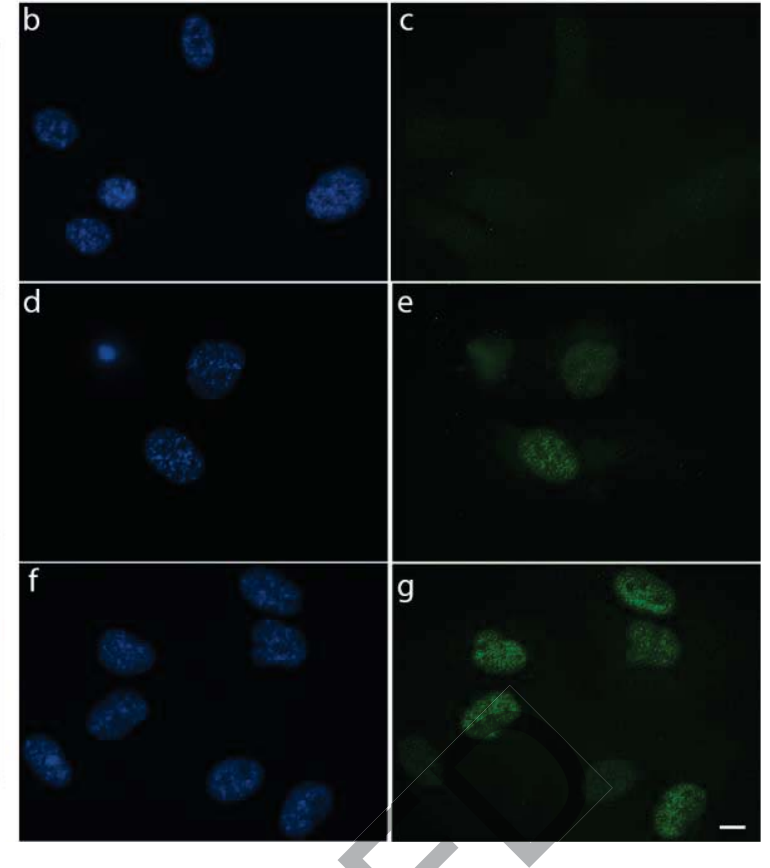

d 


\section{Figure captions}

Figure 1. Physical and chemical characterizations of the different morphologies of $\mathrm{TiO}_{2}$ NPs. Top: Transmission Electron Microscopy images of P25 and synthesized $\mathrm{TiO}_{2} \mathrm{NPs}_{\mathrm{s}}$ (TNs, NNs and INPs) and their respective size distributions based on at least 300 NPs. Down: Physical characteristics ${ }^{\mathrm{a}}$ From TEM, ${ }^{\mathrm{b}}$ From XRD, ${ }^{\mathrm{c}} \mathrm{A}=$ Anatase, $\mathrm{R}=$ Rutile, HT $=$ Hydrogen Titanate, $\mathrm{B}=$ Brookite, ${ }^{\mathbf{d}}$ From DLS analysis, ${ }^{\mathrm{e}}$ From calculations or BET analysis.

Figure 2. Effect of $\mathrm{TiO}_{2}$ NPs morphologies (P25, INPs, NNs, TNs) on human cell proliferation. Relative cell proliferation of a) HUVEC and b) HEKn. Exposure dose is 2 $\mu \mathrm{g} . \mathrm{cm}^{-2}$. Asterisks indicate significant differences with untreated groups at respectively day 8 (HUVEC) and day 10 (HEKn) (Kruskal-Wallis test (*: p<0.05; (*): p<0.06) and Nemenyi post hoc test.

Figure 3. $\mu$-PIXE analysis of HUVEC and HEKn after incubation with different $\mathrm{TiO}_{2}$ NPs (P25, INPs, NNs, TNs). a-b) Chemical mapping of the titanium intracellular content in HUVECs (a) and HEKn (b). The distribution maps for phosphorus and titanium are depicted. 2-dimensional mapping of distributions and intracellular contents of Phosphorus (P) and titanium (Ti) are expressed in gray scale and in false color scale (blue-green-red), respectively. Merge of $\mathrm{P}$ and Ti distributions. Scale bar: $10 \mu \mathrm{m} . \mathrm{c}$ ) Intracellular titanium content per cell in HUVEC (top), HEKn (middle) (dose of exposure: $2 \mu \mathrm{g} \cdot \mathrm{cm}^{-2}$ ) and in HEKn (down) (dose of exposure: $10 \mu \mathrm{g} \cdot \mathrm{cm}^{-2}$ ). (n) corresponds to the number of cells analyzed per condition. Asterisks over distributions indicate significant differences with untreated groups (Kruskal-Wallis test $(p<0.05)$ and post hoc Nemenyi test $(\mathrm{p}<0.05))$. When not specified, experiments were performed 16 to $20 \mathrm{~h}$ after exposure with $2 \mu \mathrm{g} . \mathrm{cm}^{-2}$ of $\mathrm{TiO}_{2} \mathrm{NPs}$. Controls correspond to untreated cell populations. 
Figure 4. Effect of the $\mathrm{TiO}_{2} \mathrm{NPs}$ on cellular homeostasis. Single cell quantitative analysis of the intracellular titanium (in $\mu \mathrm{g} . \mathrm{cm}^{-2}$ ) and calcium concentrations (in mg. $\mathrm{g}^{-1}$ ) measured by $\mu$-PIXE in HUVEC exposed to $2 \mu \mathrm{g} . \mathrm{cm}^{-2}$ of different $\mathrm{TiO}_{2} \mathrm{NPs}$ morphologies (P25, INPs, NNs and TNs). A black dot corresponds to one cell. The heterogeneity of the titanium intracellular content per cell is also well depicted. Relations between calcium and titanium contents were evaluated using a linear model with ordinary least square regression (red) or robust fitting (green). Asterisks indicate significant positive slopes for linear model $(p<0.05)$.

Figure 5. Effect of $\mathrm{TiO}_{2}$ NPs on the mitochondria. a-b) The mitochondrial membrane potential $(\Delta \Psi \mathrm{m})$ was monitored using TMRM staining. The intensity of TMRM fluorescence was detected using live cell imaging and fluorescent microscopy. HUVEC cells were loaded with TMRM $(500 \mathrm{nM})$ during 30 min after 6 hours exposure with 2 $\mu$ g.cm ${ }^{-2}$ of $\mathrm{TiO}_{2}$ NPs. a) HUVEC cells (control). b) HUVEC cells exposed to TNs (2 $\mu \mathrm{g} . \mathrm{cm}^{-2}, 6$ hours). Scale bar: $10 \mu \mathrm{m}$. c-f) Transmission electron microscopy analysis of HeLa and HUVEC cells exposed to $2 \mu \mathrm{g} \cdot \mathrm{cm}^{-2}$ for 20 hours to diverse morphologies of $\mathrm{TiO}_{2}$ NPs. c-d) HeLa cells with TNs (c) and P25 (d). e-f) HUVEC exposed to TNs. $\mathrm{TiO}_{2}$ NPs are visualized as dark and dense aggregates. Arrows signal damaged mitochondria $(*)$. Scale bar: $500 \mathrm{~nm}$.

Figure 6. Time-dependent induction of ER stress markers related to the level of $\mathrm{TiO}_{2}$ NPs toxicity in HUVEC. a). Time-response of Erdj4, CHOP and Herpud 1 transcript levels induced by $\mathrm{TiO}_{2} \mathrm{NPs}$ at $2 \mu \mathrm{g} \cdot \mathrm{cm}^{-2}$. The results are expressed as mean of at least three independent experiments. ${ }^{*} \mathrm{P}<0.01$ compared to the control. b-g.) in cellulo detection of CHOP, a specific ER stress marker in HUVEC cells. Paraformaldehydefixed cell nuclei are stained by Hoechst ${ }^{33342}$ (blue, b, d, f) and counterstained with antimurine antibody targeted to the human protein CHOP (L63F7, Cell Signaling) coupled to Goat anti-mouse AF488 secondary antibody (green, c, e, g). b, c) HUVEC cells (control). d, e) HUVEC cells exposed to $2 \mu \mathrm{g} . \mathrm{cm}-2$ of TNs during 16 hours. f, g) 
Positive-control used to specifically induced CHOP expression and specific subcellular localization by incubating cells 20 hours to Tunicamycin $\left(5 \mu \mathrm{g} \cdot \mathrm{mL}^{-1}\right)$. Scale bar: $10 \mu \mathrm{m}$ 